Article

\title{
The Identification of Factors Affecting the Use of Pressurized Irrigation Systems by Farmers in Iran
}

\author{
Abdullah Momvandi $@$, Maryam Omidi Najafabadi *, Jamal F. Hosseini and Farhad Lashgarara \\ Department of Agricultural Extension and Education, Science and Research Branch, Islamic Azad University, \\ Tehran, Iran; abdollahmomvandi@yahoo.com (A.M.); jamalfhosseini@srbiau.ac.ir (J.F.H.); \\ f.lashgarara@srbiau.ac.ir (F.L.) \\ * Correspondence: m.omidi@srbiau.ac.ir; Tel.: +98-9122391224
}

Received: 10 August 2018; Accepted: 4 October 2018; Published: 27 October 2018

\begin{abstract}
Climate change and water scarcity are the most important challenges of the agricultural sector, and pressurized irrigation systems (PISs) are one of the most significant ways to improve agricultural water productivity. The main purpose of this research was to identify the factors affecting the use of PISs by farmers. The statistical research population was a total of 2396 Iranian model farmers. The Cochran formula was used to determine the number of statistical samples. Accordingly, this comprised 331 people. The methodology of the study was mixed method research. The structural equation modeling technique, Mann-Whitney $\mathrm{U}$, and Kruskal-Wallis tests were used to test the hypotheses. The results showed that the personal characteristics, tendency, attitude, self-efficacy, subjective norms, governmental support, environmental tensions, and technological features were the most important factors which influenced the farmers. It was found that all of these variables had a positive and significant relationship with the using of PISs by farmers, and they were able to predict $52 \%$ of the behavioral changes $\left(R^{2}\right)$ of the farmers. Among these variables, the attitude, with a path coefficient $(\beta)$ of 0.48 , had the highest impact on the using of PISs by the farmers.
\end{abstract}

Keywords: irrigation efficiency; water productivity; pressurized irrigation systems; model farmers; behavior; structural equation modeling (SEM)

\section{Introduction}

The 'Falkenmark indicator' or 'water stress index' is one of the key indicators for determining the water crisis in the world. Based on this index and other indicators such as those provided by the United Nations and the International Water Management Institute, Iran faces a serious water crisis [1]; Iran, with an average annual precipitation of $260 \mathrm{~mm}$, is considered an arid area. An annual rate of $7000 \mathrm{~m}^{3}$ of renewable water in 1956 declined to $2000 \mathrm{~m}^{3}$ in 1996 , and it is predicted to be reduced to $800 \mathrm{~m}^{3}$ by 2020. This is lower than the water scarcity level (i.e., $1000 \mathrm{~m}^{3}$ ) [2]. Due to global warming in the next 40 years, the air temperature in Iran will increase by about $2{ }^{\circ} \mathrm{C}$ and the annual rainfall will be reduced by about $50 \mathrm{~mm}$ [3]. Furthermore, Iran's agricultural sector consumes approximately $92 \%$ of the available water, but the average irrigation efficiency (IE) in this sector is only 35\% [4]. Moreover, with a one-percent increase in the water productivity of Iran's agricultural sector, 1.25 billion cubic meters of water can be saved [5].

Water productivity is one of the most important issues in the agricultural sector. Molden et al. [6] stated: "In a broad sense, productivity of water is related to the value or benefit derived from the use of water. Definitions of water productivity differ based on the background of the researcher or stakeholder. For example, obtaining more kilograms per unit of transpiration is an important means of expressing productivity of water when the interest of analysis is crops". The average world water 
productivity is reported to be between 1.8 and $2 \mathrm{~kg} / \mathrm{m}^{3}$ per hectare, while its rate in Iran is only 0.8 to $1.1 \mathrm{~kg} / \mathrm{m}^{3}$ per hectare [7].

Irrigation engineers, when designing an irrigation system, try and maximize irrigation efficiency (IE); IE is defined as the ratio of the volume of water that is taken up by the crop to the volume of irrigation water applied [8]. The IE is 30\% in traditional methods [5], but drip irrigation has the potential to increase IE because the farmer can apply light and frequent amounts of water to meet crops' evapotranspiration needs. The IEs ranged from 80 to $91 \%$ when the crop was grown in fields using a surface drip system [8]. IEs ranged from 54 to $80 \%$ with a sprinkler irrigation system, and IEs under furrow irrigation were between 50 and $73 \%$ [8]. The average IE in the world is $65 \%$, but in Iran, it is only $35 \%[4,5]$.

Experts have presented different ways to solve the water productivity in Iran's agricultural sector, but most of them recommend the use of pressurized irrigation systems (PISs) [1,9-12]. In the PISs, water is pressurized and precisely applied to the plants under pressure through a system of pipes. There are many variations of PISs, but the two major ones are drip irrigation systems and sprinkler systems [13]. Water use efficiency is very different between these methods. This efficiency for flood irrigation, furrow irrigation, sprinkler irrigation, rain irrigation, and drip irrigation is $40-70 \%, 50-75 \%$, $80-85 \%, 60-90 \%$, and $85-92 \%$, respectively [14].

The total of Iran's suitable agricultural land area for the implementation of PISs is 8.7 million hectares, but only 1.4 million hectares (16.1\%) of this have been covered by these systems, and $83.9 \%$ are irrigated by using traditional methods [15]. Although Iran was one of the first countries in the world to use PISs, these systems have not been well developed. Therefore, the lack of PIS development in Iran has caused significant losses of water resources. Due to the importance of developing PISs in Iran and other countries, the main goals of this research are: identifying the factors affecting the use of PISs by farmers and investigating the type of relationships and impact of identified factors on farmers' behavior.

The research area included all the provinces of Iran, so it is possible to generalize the results throughout Iran and even countries that have climatic, cultural, and social conditions similar to Iran, such as Afghanistan, Pakistan, Turkmenistan, Azerbaijan, Armenia, Syria, Israel, Turkey, Saudi Arabia, Egypt, United Arab Emirates, Iraq, Qatar, Lebanon, Jordan, Kuwait, and Bahrain. These results provide valuable information for agricultural sector managers and decision-makers in Iran and similar countries with which to extend the PIS use among farmers and thereby improve the water productivity of the agricultural sector.

\section{Materials and Methods}

The methodology of the study was mixed method research. Mixed method research is a methodology for conducting research that involves selecting, analyzing, and integrating qualitative and quantitative research. This approach to research is used when this integration provides a better understanding of the research problem than either methodology alone. The required information was collected in the qualitative phase through literature studies and in the quantitative phase through questionnaires.

In the qualitative phase, the most important factors were identified and synthesized. In the quantitative phase, the type of relationships and their impact on farmers' behavior were investigated.

The research lasted for 26 months from 22 September 2014 to 21 November 2016, and the research area was the whole of Iran.

The statistical population of the study was comprised of model Iranian farmers, from 2011 to 2015. These individuals, known as "master" or "led" farmers, are also those who have succeeded in obtaining the first place in the selection process of the model farmers, which is conducted annually by Iran's Ministry of Agriculture Jihad. The most important reasons for choosing these people as a statistical population were courage, literacy, higher innovation, more communication with experts and 
extension agents, and the role they played as leaders of thought in local communities in comparison with other farmers.

The number of the statistical population was 2396, and the statistical sample number as determined by the Cochran formula is 331 (Table 1). The sampling method was cluster sampling. Each province was a cluster, and the sampling method in each cluster was random sampling.

Table 1. The number of the statistical population and sample for research in different provinces of Iran.

\begin{tabular}{|c|c|c|c|c|c|}
\hline Province & Population (N) & Sample (n) & Province & Population (N) & Sample (n) \\
\hline East Azarbaijan & 111 & 15 & Fars & 132 & 19 \\
\hline West Azarbaijan & 112 & 15 & Ghazvin & 49 & 7 \\
\hline Ardabil & 42 & 6 & Qom & 28 & 2 \\
\hline Esfehan & 137 & 19 & Kordestan & 63 & 9 \\
\hline Alborz & 50 & 7 & Kerman & 75 & 11 \\
\hline Ilam & 65 & 9 & Kermanshah & 93 & 13 \\
\hline Boshehr & 59 & 8 & Kohkiloyeh and Boyerahmad & 52 & 7 \\
\hline Tehran & 84 & 12 & Golestan & 25 & 5 \\
\hline Cheharmahal and Bakhtiary & 46 & 6 & Gilan & 67 & 9 \\
\hline South Khorasan & 64 & 9 & Lorestan & 74 & 10 \\
\hline Razavi Khorasan & 123 & 17 & Mazandaran & 61 & 8 \\
\hline North Khorasan & 72 & 10 & Markazi & 97 & 13 \\
\hline Khozestan & 103 & 14 & Hormozgan & 83 & 11 \\
\hline Zanjan & 69 & 9 & Hamadan & 68 & 9 \\
\hline Semnan & 68 & 9 & Yazd & 61 & 8 \\
\hline Sistan and Balochestan & 77 & 11 & Jiroft & 86 & 11 \\
\hline Total & \multicolumn{2}{|c|}{$\mathrm{N}(2396)$} & \multicolumn{3}{|c|}{ n (331) } \\
\hline
\end{tabular}

In order to determine the validity, the questionnaire provided was approved by the faculty members of the Agricultural Extension and Education Department, Faculty of Agriculture, Science and Research Branch, Tehran. A sequential theta formula was used to determine its reliability. For this, as the pretest, a questionnaire prepared in the Lorestan province was distributed among and calculated for 30 model farmers in this province. The result showed that the amount of sequential theta for different parts of the questionnaire had a minimum of 0.74 and maximum of 0.89 .

\section{Identification of the Factors Affecting the Use of PISs by Farmers}

In order to identify the factors affecting farmers' behavior and design a behavioral model of PIS use by farmers, behavioral theories/models and field studies were collected and analyzed using the systematic review method (Table 2).

The theories/models selected and analyzed in this study were the theory of rational action (TRA), the theory of planned behavior (TPB), the social recognition theory (SCT), the health belief model (HBM), the innovations decision-making theory (ID), the technology acceptance model (TAM), the unified theory of acceptance and application of technology (UTAUT), and the integrated behavioral model (IBM). The results of the study on behavioral theories/models showed that in TRA, the intention of a person to show a behavior is a function of two variables: individual attitude and mental norms [16]. In $\mathrm{TPB}$, the probability of showing a behavior is greater when attitude and subjective norms are favorable and there is a higher perceived behavioral control on the behavior [17]. In SCT, the impact of attitudes, beliefs, and environmental influences is measured in behavioral measurement so that a person, through the observation of others, can form the idea of how to show new behaviors and, in later situations, can use this information as guidance for action [18]. In HBM, if a person becomes aware of a disease or its consequences as being a threat, the motive for action is created in him to avoid the threat from that disease [19]. In ID, the features of the relative advantages, compatibility, complexity, testability, and visibility of technology are effective in its acceptance [20]. In TAM, usefulness and ease of use were mentioned as determinants of the use of a technology [21]. In UTAUT, the abstract variables of critical and possible factors are related to the prediction of the behavioral intention to use a technology and the basic application of organizational contexts, and control variables such as the age, gender, and degree/education level have also been used [15]; and finally, in IBM, knowledge and skills 
have been identified for behavior implementation, behavior prominence, environmental coercions, and habits [6].

In examining the field studies, economic and social factors $[2,10,21,22]$ as well as individual and social characteristics such as location, age, work experience, education, awareness, financial resources [9,11,23]; literacy rate, land area, ownership, and farmers' awareness [24,25]; the level of social participation and technical knowledge of farmers [26,27]; education-extensional programs [10,16,22,24,26]; giving subsidies and services and bank credits [27]; access to supplies and equipment [6]; government support [13,28]; smallness and dispersion of crops parts $[11,29,30]$; drought and water scarcity [13]; and non-environmental factors such as age, gender, education, technical knowledge, and the family labor force $[10,22,24,31]$ were found to have an impact on farmers' behavior of using systems.

Table 2. Most important factors affecting the use of PISs by farmers (latent and obvious variables).

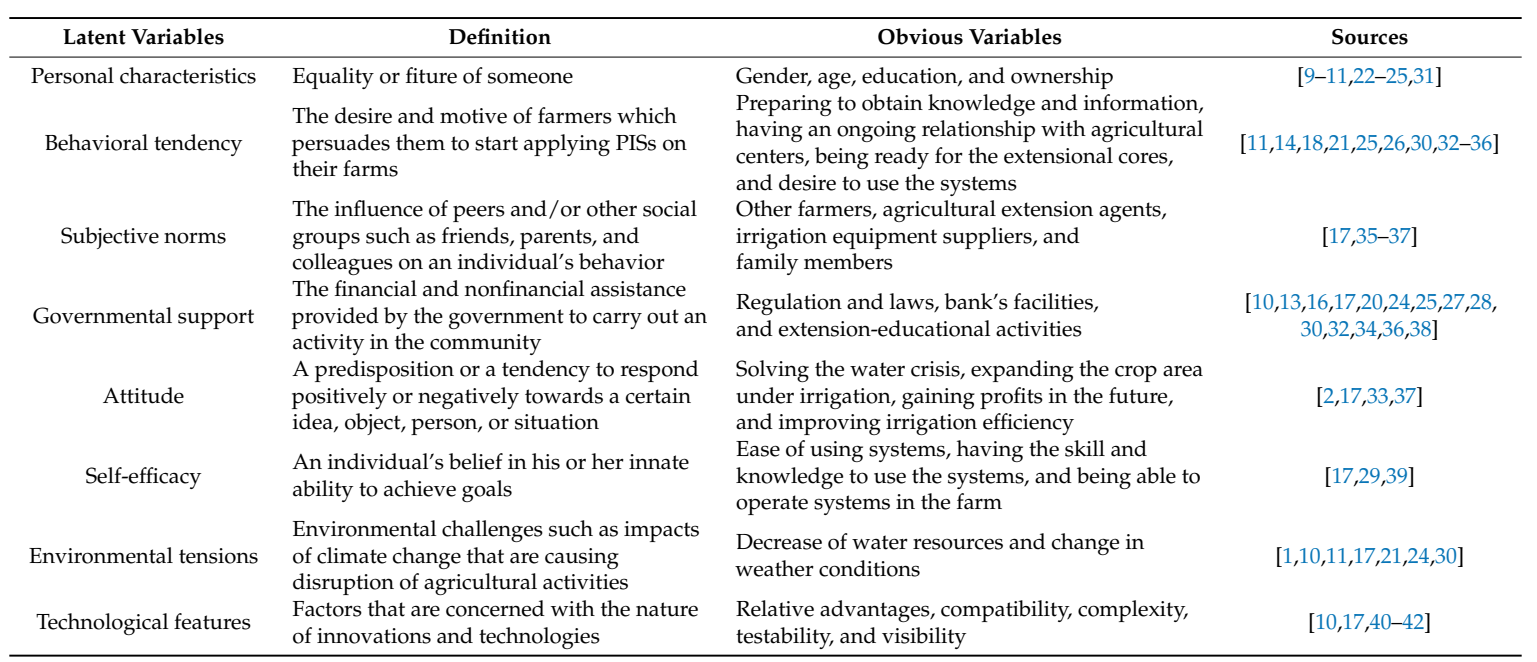

\section{Research Questions}

(1) Do farmers with different personal characteristics such as age, gender, education, and ownership have similar behaviors in accepting PISs?

(2) Do subjective norms, governmental support, technological features, and environmental stresses as well as farmers' tendency, attitude, and self-efficacy have a significant impact on their behavior of using PISs?

\section{Data Analysis and Results}

\subsection{Descriptive Statistical Perspective}

Overall, $96.4 \%$ of the subjects were male and $3.6 \%$ were female. Regarding age, $2.7 \%$ of subjects were in the age group below 30 years; $14.2 \%$ were in the age group of $31-40$ years, $28.7 \%$ were in the age group of $41-50$, and $30.8 \%$ were in the age group of $51-60$ years. Regarding education, $2.4 \%$ of subjects were illiterate, $9 \%$ had the ability to read and write, $13.3 \%$ had primary education; $17.8 \%$ had secondary education, $34 \%$ had a high school diploma, and $23.2 \%$ had a university degree. In terms of land ownership, 29\% had less than 10 ha, 19.6\% between 11 and 20 ha, 19.3\% between 21 and 30 ha, $9.1 \%$ between 31 and 40 ha, $7.3 \%$ between 41 and 50 ha, and 15.7\% had more than 50 ha. In total, $73 \%$ of the respondents had used PISs (Table 3). 
Table 3. The societal status of the statistical sample of the research.

\begin{tabular}{|c|c|c|c|c|c|c|c|}
\hline Gender & \multicolumn{4}{|c|}{ Male } & \multicolumn{3}{|c|}{ Female } \\
\hline No. persons & \multicolumn{4}{|c|}{319} & \multicolumn{3}{|c|}{12} \\
\hline Age groups & \multicolumn{2}{|c|}{$<30$ years } & $31-40$ years & $\begin{array}{c}41-50 \text { years } \\
95\end{array}$ & \multicolumn{2}{|c|}{$51-60$ years } & $\begin{array}{c}>60 \text { years } \\
78\end{array}$ \\
\hline Education level & Illiterate & $\begin{array}{l}\text { Able to read } \\
\text { and write }\end{array}$ & $\begin{array}{l}\text { Primary } \\
\text { education }\end{array}$ & $\begin{array}{l}\text { Secondary } \\
\text { education }\end{array}$ & $\begin{array}{l}\text { High school } \\
\text { diploma }\end{array}$ & \multirow{2}{*}{$\begin{array}{c}\text { Bachelor's } \\
\text { degree } \\
65\end{array}$} & $\begin{array}{l}\text { Master's degree } \\
\text { and higher }\end{array}$ \\
\hline No. persons & 8 & 30 & 44 & 59 & 113 & & $12^{\circ}$ \\
\hline Acceptance of PISs & \multirow{2}{*}{\multicolumn{3}{|c|}{$\begin{array}{l}\text { Acceptance } \\
241\end{array}$}} & \multicolumn{4}{|c|}{ No acceptance } \\
\hline No. persons & & & & & & 90 & \\
\hline
\end{tabular}

\subsection{Inferential Statistics Perspective}

5.2.1. Influence of Individual Characteristics (Age, Gender, Education, and Ownership) on Farmers' Behavior

To study the influence of individual characteristics on farmers' behavior, nonparametric tests such as the Mann-Whitney U test and Kruskal-Wallis test were used. The results showed that:

- There is no significant difference between the PIS usage behaviors of farmers and their gender at the $95 \%$ level.

- There is no significant difference between the PIS usage behaviors of farmers and their age at the $95 \%$ level.

- There is a significant difference between the PIS usage behaviors of farmers and their education level at the $99 \%$ level.

- There is a significant difference between the PIS usage behaviors of farmers and the land ownership at the $99 \%$ level (Table 4 ).

Table 4. The results of the Mann-Whitney U and Kruskal-Wallis tests for hypotheses 1-4.

\begin{tabular}{ccc}
\hline Hypothesis Number & & PIS Usage Behaviors of Farmers \\
\hline & Whitney-U & 1605.000 \\
$\mathrm{H}_{1}$ & W-Wilcoxon & $52,645.000$ \\
& Z & -1.154 \\
& Asymp.sig & 0.249 \\
& Chi-squared & 6.275 \\
$\mathrm{H}_{2}$ & DF & 4 \\
& Asymp.sig & 0.179 \\
& Chi-squared & 17.331 \\
$\mathrm{H}_{3}$ & DF & 6 \\
& Asymp.sig & 0.008 \\
& Chi-squared & 8.759 \\
$\mathrm{H}_{4}$ & DF & 5 \\
& Asymp.sig & 0.019 \\
\hline
\end{tabular}

Therefore, hypotheses number one and two are rejected and assumptions number three and four are confirmed.

5.2.2. The Impacts of the Obvious Variables on the Latent Variables (Tendency, Attitude, Self-Efficacy, Subjective Norms, Governmental Support, Environmental Tensions, and Technological Features) of the Research

To study the impact of obvious variables on the latent variables and the impact of latent variables on the behavior of farmers, the structural equation modeling (SEM) method has been used (Figure 1). 
SEM uses various types of models to depict relationships among observed variables, with the somewhat basic goal of providing a quantitative test of a theoretical model hypothesized by the researcher. More specifically, various theoretical models can be tested in SEM that hypothesize how sets of variables define constructs and how these constructs are related to each other [15].

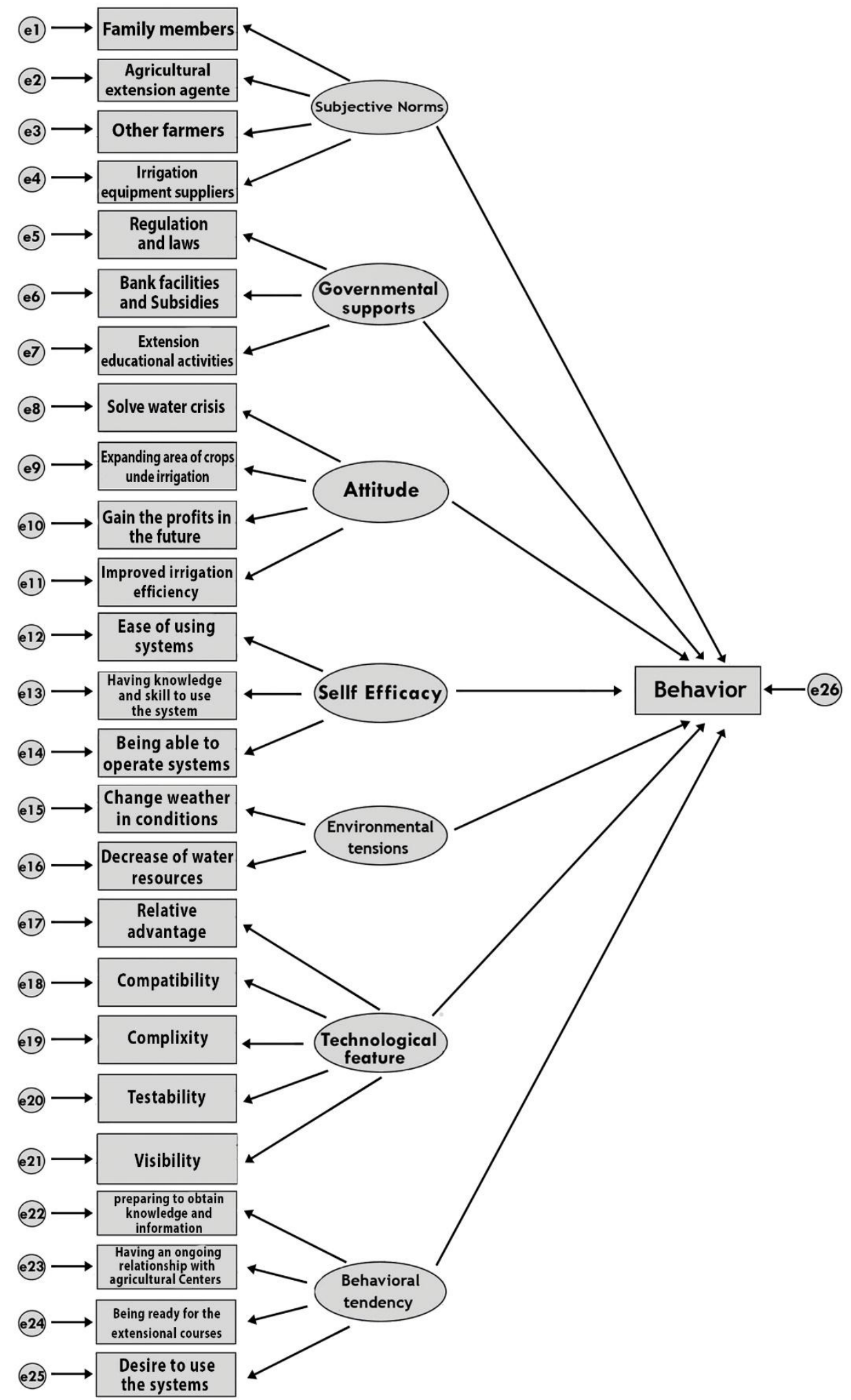

Figure 1. The conceptual model of the behavior of using PISs of farmers. 
Results showed that agricultural extension agents have the highest impact on farmers' subjective norms $(\beta=0.78)$; regulation and laws have the highest impact on governmental support $(\beta=0.61)$; expanding the crop area under irrigation has the highest impact on farmers' attitude $(\beta=0.72)$; having the skill and knowledge to use the systems has the highest impact on self-efficacy $(\beta=0.87)$; the decreasing of water resources has the highest impact on environmental tensions $(\beta=0.20)$; compatibility has the highest impact on technological features $(\beta=0.63)$; and desire to use the systems has the most impact on behavioral tendency $(\beta=0.65)$.

In addition, it was found that in all cases, the obvious and the latent variables (at $95 \%$ and $99 \%$ levels) had a positive and significant relationship (Table 5).

Table 5. Significance test of the relationships between latent variables and visible variables.

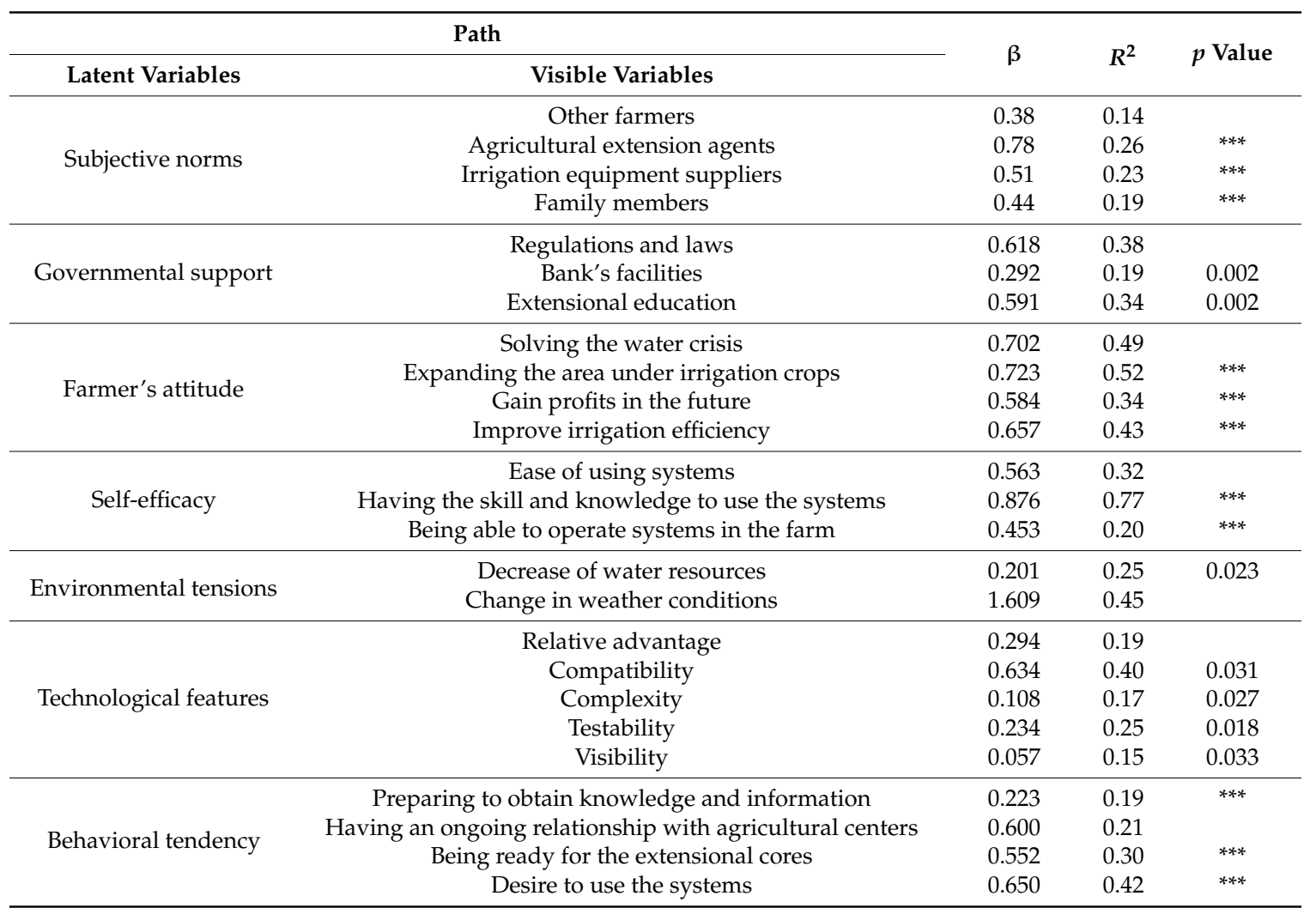

Note: ${ }^{* * *}$ The mean difference is significant at the 0.01 level.

\subsubsection{The Impact of Latent Variables on the Behavior of Farmers}

The impact of the attitude, self-efficacy, subjective norms, environmental tension, and governmental support on the farmer's behavior at the $99 \%$ level was positive and significant.

The impact of technological features and tendency on farmers' behavioral at the $95 \%$ level was also positive and significant. Therefore, all hypotheses 5-11 were confirmed (Table 6 and Figure 2).

Among the variables of subjective norms, tendency, attitude, self-efficacy, governmental support, technological features, and environmental tensions, the attitude variable had the highest impact ( $\beta=0.048)$ on the behavior of farmers (Table 6 and Figure 2). 


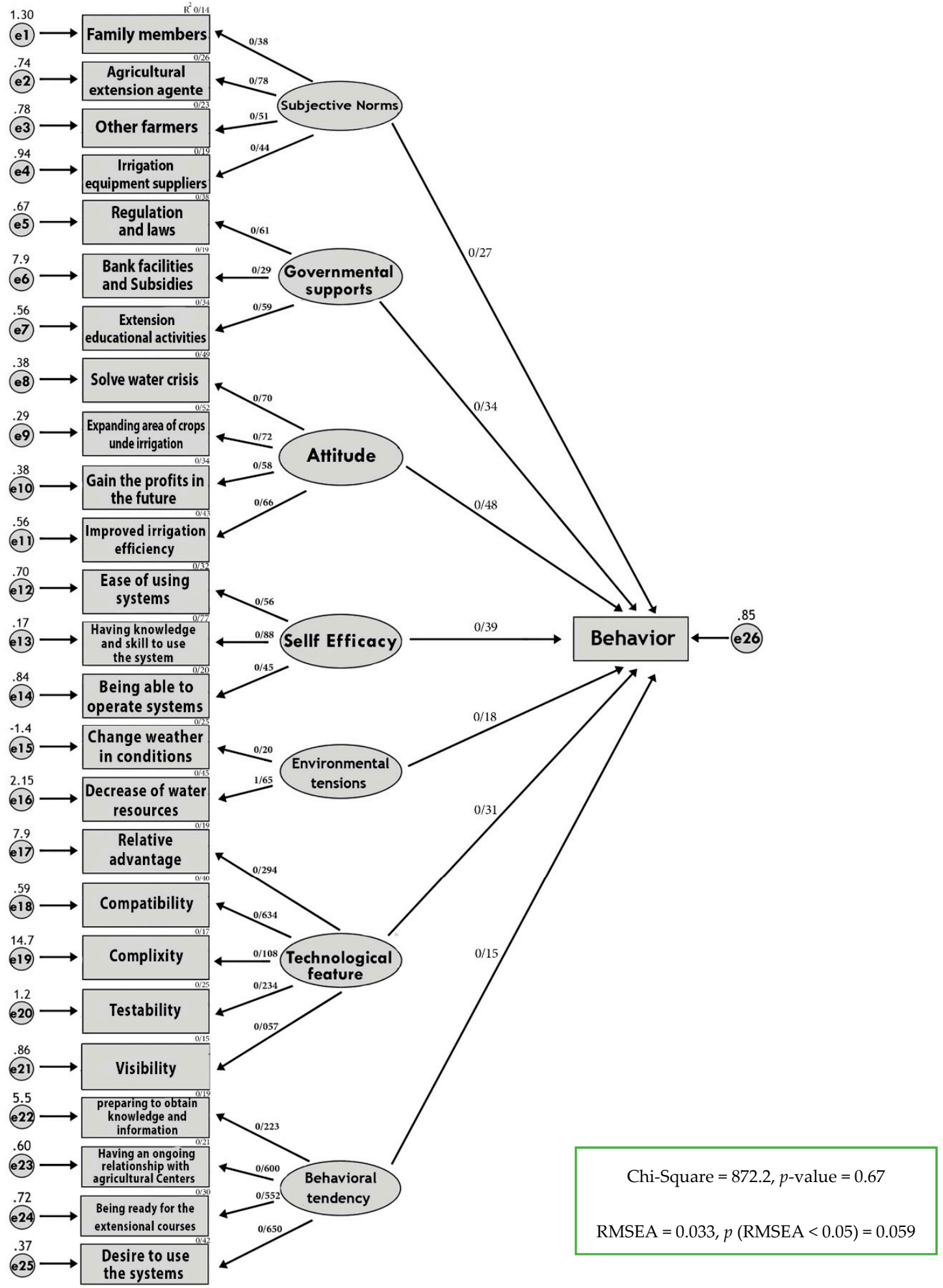

Figure 2. Final model of the behavior of using PISs of farmers. 
Table 6. Significance test of latent variables' paths to behavior.

\begin{tabular}{|c|c|c|c|c|c|c|}
\hline Hypothesis Number & Path & $\beta$ & $R^{2}$ & SE & CR & $p$ Value \\
\hline $\mathrm{H}_{5}$ & Subjective norms to behavior & 0.27 & & 0.142 & 2.887 & 0.004 \\
\hline $\mathrm{H}_{6}$ & Governmental support to behavior & 0.34 & & 0.132 & 2.512 & 0.012 \\
\hline $\mathrm{H}_{7}$ & Attitude to behavior & 0.48 & & 0.132 & 2.517 & $* * *$ \\
\hline $\mathrm{H}_{8}$ & Self-efficacy to behavior & 0.39 & 0.52 & 0.082 & 3.442 & $* * *$ \\
\hline $\mathrm{H}_{9}$ & Environmental tensions to behavior & 0.18 & & 0.056 & 0.153 & 0.034 \\
\hline $\mathrm{H}_{10}$ & Technological features to behavior & 0.31 & & 0.016 & 1.231 & 0.052 \\
\hline $\mathrm{H}_{11}$ & Tendency to behavior & 0.15 & & 3.408 & 2.045 & 0.041 \\
\hline
\end{tabular}

Note: SE: standard error; CR: construct reliability; ${ }^{* * *}$ the mean difference is significant at the 0.01 level.

\subsubsection{Fitness Indexes of the Final Model of the Behavior of Using PISs of Farmers}

We also examined absolute fit indexes. The chi-squared value $\left(X^{2}\right)$, root mean square error of approximation (RMSEA), goodness-of-fit statistic (GFI), the adjusted goodness-of-fit statistic (AGFI), degrees of freedom (df), and $\mathrm{df} / \mathrm{X}^{2}$ were used to test the fitting of the model. The result shows that this model, in the indexes examined, had good fitness (Table 7).

Table 7. Fitness indexes of the final model of the behavior of using PISs of farmers.

\begin{tabular}{ccccccccc}
\hline Index & $\boldsymbol{X}^{\mathbf{2}}$ & DF & P Cmin & df $/ X^{\mathbf{2}}$ & RMSEA & P-Close & GFI & AGFI \\
\hline Acceptable level & - & - & $<0.05$ & $<3$ & $<0.05$ & $>0.05$ & $>0.9$ & $>0.9$ \\
The observed value & 872.2 & 293 & 0.067 & 2.977 & 0.033 & 0.059 & 0.81 & 0.80 \\
Fitness assessment & & & fit & fit & fit & fit & fit & fit \\
\hline
\end{tabular}

Note: $X^{2}$ : the chi-squared value; DF: degree of freedom; P Cmin: the symbol of the $X^{2}$ in Amos; RMSEA: root mean square error of approximation; GFI: goodness-of-fit statistic; AGFI: the adjusted goodness-of-fit statistic; -: there is no acceptable level.

\section{Conclusions and Discussion}

This research identified the most important factors affecting the use of PISs by farmers in Iran. In this research, firstly, the most important factors influencing the use of PISs by farmers were identified. In order to identify the factors affecting farmers' behavior, behavioral theories/models and field studies were collected and analyzed by using the systematic review method. The results showed that personal characteristics, tendency, attitude, self-efficacy, subjective norms, governmental support, environmental tensions, and technological features are the most important factors which affect farmers.

In the next stage, the relationships between individual characteristics and the usage of PISs by farmers were investigated. The results showed that there is no significant difference between the use of PISs by farmers and their gender and age, but there is a significant difference between the use of PISs by farmers and their education and land ownership. These cases have already been examined by Afrakhteh et al. [31], Aghapour and Ostvar [24], Balali et al. [23], Gholamrezaei et al. [11], Shahzadi [25], and Yosefinejhad et al. [22]. They have stated that there is a positive and significant relationship between these variables and the using of PISs by farmers. As the small and scattered nature of agricultural land is one of the serious problems of agricultural development in Iran and many other countries, it is recommended that the agricultural land consolidation plan be taken seriously. On the other hand, since farmers usually have lower levels of education and their average age is also high, they cannot be educated through formal methods. Therefore, it can be suggested that extension-educational activities should be considered seriously in order to increase the knowledge and skills of farmers.

In the third step of the study, the impact of factors affecting the use of PISs by farmers have been investigated through a structural equation modeling (SEM) method. The results showed that subjective norms are the influence of peers or other social groups such as friends, parents, and colleagues on an individuals' behavior. The relationship between subjective norms and use of PISs by farmers has been investigated by Taqipour et al. [35] and its positive and significant relationship has been confirmed. 
This relationship has also been studied in this research, and its positive and significant relationship has been reaffirmed. In addition, it was found that among variables such as other farmers, agricultural extension agents, irrigation equipment suppliers, and family members, agricultural extension agents have a greater impact on farmers' behavior. This issue proves the importance of the role of agricultural extension agents in helping to develop the agricultural sector.

Governments, in most countries of the world, usually support the development of PISs by farmers. This support takes place in different ways in different countries such as by setting rules and regulations, and giving subsidies, bank credits, and extension-educational activities. Abdolmaleki and Chizari [32], Amiri and Zamani [27], Arayesh [10], Hosseini and Dehyori [16], Glanz et al. [17], Jahannama [20], Madhava Chandran and Surendran [28], Norozi and Chizari [34], Shahzadi [25], Shateryan et al. [13], Surendran [30], and Venkatesh et al. [36] in their studies have examined the relationship between governmental support and use of PISs by farmers. They say there is a positive and meaningful relationship between these two variables. In this study, this relationship has been examined too. The results showed that governmental support in Iran has a positive, significant, and acceptable relationship with the use of PISs by farmers, and that governmental rules and regulations have the highest impact on farmers' behavior. We recommend that governments facilitate the farmers' access to the services provided (by reducing their administrative bureaucracies).

The theory of self-efficacy was presented by Albert Bandura [39]. Self-efficacy is an individual's belief in his or her innate ability to achieve goals. Little research has been done on the effects of self-efficacy on farmers' behaviors. Amini [29] examined the relationship between self-efficacy and the using of PISs by farmers and says "there is a positive and meaningful relationship between these two variables. It also investigated in this study and was approved.

Attitude refers to a set of emotions, beliefs, and behaviors toward a particular object, person, thing, or event and it is always considered as an important factor in the direction of human behavior. Afshar and Zarafshani [33], Glanz et al. [17], Shahzadi [25], and Tohidifar and Rezaei [2] in their studies examined the relationship between the attitude and using of PISs by farmers. They say there is a positive and meaningful relationship between these two variables. This study also examined this relationship. The result showed that attitude in Iran has a positive, significant, and acceptable relationship with the use of PISs by farmers. The most important point is that among variables such as tendency, self-efficacy, subjective norms, governmental support, environmental tensions, and technological features, this variable (attitude) has the highest impact on farmers' use of PISs.

Climate change and environmental tensions are the most important factors in decision-making by farmers to determine the type of cultivation and selection of irrigation methods. Scientists consider this variable to be one of the most important challenges in human life in the 21st century, and they have done a lot of research on anticipating and confronting it. Aghapour and Ostvar [24], Arayesh [10], Gholamrezaei et al. [11], Karami [21], Surendran [30], and Taghvaei and Boshagh [1] have examined the relationship between environmental tensions and use of PISs by farmers. They say there is a positive and meaningful relationship between these two variables. This study also has examined this relationship. The results showed that environmental tensions in Iran have a positive, significant, and acceptable relationship with the use of PISs by farmers. What needs to be considered is that farmers are more concerned with the short-term effects of environmental tensions than long-term effects. Therefore, it is suggested that farmers' information about the long-term effects of the climate change and the ways of coping with them can be enhanced through providing educational training activities.

Technological features are the factors concerned with the nature of innovations and technologies. They include the relative advantages, compatibility, complexity, testability, visibility, and effect on the process of transferring and disseminating new technologies among farmers. Sharma and Roams [40] and Arayesh [10] have examined the relationship between technological features and use of PISs by farmers. They say there is a positive and meaningful relationship between these two variables. This case also has been examined in this study. The results showed that technological features in Iran have a positive, significant, and acceptable relationship with the use of PISs by farmers. In addition, it was 
found that the compatibility feature has a greater effect on farmers' behavior than other technological features. Therefore, compatibility of systems with farmers' conditions should be taken in to account while introducing PISs to them.

These results provide valuable information for agricultural sector managers and decision-makers in Iran and other countries having climatic, cultural, and social conditions that are similar to Iran, such as Afghanistan, Pakistan, Turkmenistan, Azerbaijan, Armenia, Syria, Israel, Turkey, Saudi Arabia, Egypt, United Arab Emirates, Iraq, Qatar, Lebanon, Jordan, Kuwait, and Bahrain, to extend the use of PISs among farmers and thereby improve the water productivity of the agricultural sector.

Author Contributions: Conceptualization, A.M. and M.O.N.; methodology, A.M., M.O.N., J.F.H. and F.L.; software, A.M.; validation, A.M., M.O.N., J.F.H. and F.L.; formal analysis, A.M. and M.O.N.; investigation, A.M.; resources, A.M., M.O.N.; data curation, A.M. and M.O.N.; writing-original draft preparation, A.M.; writing-review and editing, A.M., M.O.N., J.F.H. and F.L.; visualization, A.M. and M.O.N.; supervision, M.O.N., J.F.H. and F.L.; project administration, M.O.N.; funding acquisition, A.M.

Funding: This research received no external funding.

Conflicts of Interest: The authors declare no conflict of interest.

\section{References}

1. Taghvaei, M.; Boshagh, M. The analysis of factors affecting on non-use of under pressurized irrigation systems in Iranian villages (the case study: Azna, county). Geogr. Stud. Draught Areas J. 2011, 1, 11-23. (In Persian)

2. Tohidifar, S.; Rezaei Moghadam, K. Attitudes of farmers toward participation in irrigation and drainage projects: The structural equations modeling analysis. Iran Agric. Res. 2015, 34, 80-91.

3. Alizadeh, A. Principles of Applied Hydrology, 24th ed.; Imam Reza University Press: Mashhad, Iran, 2009. (In Persian)

4. Ehsani, M.; Khaledi, H. Water efficiency in agriculture. In Proceedings of the Eleventh Congress of Iranian Irrigation and draining National Committee, Institute for the intellectual development of children and young adults, Tehran, Iran, 23-24 December 2003; pp. 1-18. (In Persian)

5. Khalilian, S.; Mosavi, H. Risk assessment of the effect of application of under pressurized irrigation systems. J. Agric. Econ. Dev. 2002, 13, 113-129. (In Persian)

6. Mahbobi, M.; Esmaeili Eval, M.; Yaghobi, J. Barriers and driving adoption of new irrigation methods by farmers, case study: West of the city Boshrooyeh in south Khorasan. Iran. J. Water Irrig. Manag. 2011, 1, 87-98. (In Persian)

7. Heidari, N. Assessment of Agricultural Water Productivity (WP) in Iran, and the performance of water policies and plans of the Government in this regard. Majlis Rahbord J. 2014, 78, 177-200. (In Persian)

8. Al-Jamal, M.S.; Ball, S.; Sammis, T.W. Comparison of sprinkler, trickle and furrow irrigation efficiencies for onion production. Agric. Water Manag. 2001, 46, 253-266. [CrossRef]

9. Anbari, M.; Bagheri, R.; Davodi, H. Survey of social factors effecting on discontinuation of innovation in rural areas (Case study: Drip irrigation technology in Lorestan). J. Sci. Today's World 2013, 2, 451-464.

10. Arayesh, B. Studying the key factors in successes of under pressure irrigation systems (Case study: Ilam, Iran). World Appl. Sci. J. 2011, 13, 2126-2136.

11. Gholamrezaei, S.; Ebrahimi, M.S.; Aslani, M. Factors affecting the adoption of new irrigation systems by Iranian farmers. Indian J. Sci. Res. 2014, 5, 9-15.

12. Karami, E. Appropriateness of farmers' adoption of irrigation methods: The application of the AHP model. J. Agric. Syst. 2006, 87, 101-119. [CrossRef]

13. Shateryan, M.; Eshnovaei, A.; Ganjipor, M. The behavior adoption of new irrigations by Kashan plain's farmers (the case study Abuzeidabad villages area). In Proceedings of the Third Congress Plain Kashan Water Crisis, Kashan, Iran, 29 August 2011; pp. 85-99. (In Persian)

14. Gill, M.A. Water Management Practices in Pakistan. 2013. South Asian Conservation Agriculture Network (SACAN). Available online: http:/ / siteresources.worldbank.org/PAKISTANEXTN/Resources / WMPracticesinPakistan.pdf (accessed on 15 April 2015). 
15. International Commission of Irrigation and Draining (ICDI). Annual Report 2014-15. 2015. Available online: http:/ / www.icid.Org/Sprinkler (accessed on 2 November 2015).

16. Hosseini, S.J.F.; Dehyori, S. Investigating the Factors Affecting the Use of Bank Accounts in Pressure Irrigation Projects in Isfahan Province. Agric. Extens. Educ. Res. J. 2011, 1, 15-28. (In Persian)

17. Glanz, K.; Rimer, B.K.; Viswanath, K. Health Behavior and Health Reasoned Action, Theory of Planed Behavior, and the Integrated Behavioral Model; Jossey-Bass Press: San Francisco, CA, USA, 2008.

18. Green, G.; Sunding, D.; Zilberman, D.; Parker, D. Explaining irrigation Technology Choices: A Micro parameter Approach. Am. J. Agric. Econ. 2015, 78, 1064-1072. [CrossRef]

19. Jong Lee, R.; Ge, L. An Analysis of Farmers' Behavior and Reward Provision of Public Goods. 2010. Available online: http:/ / ageconsearch.Umn.edu (accessed on 4 May 2015).

20. Jahannama, F. The social and economic factors that are effect on acceptance of under pressure irrigation systems: The case study: Tehran province. Iran. J. Agric. Dev. 2001, 36, 237-260. (In Persian)

21. Karami, E. Models of soil conservation technology adoption in developing countries: The case of Iran. J. Iran Agric. Res. 1995, 14, 39-62. (In Persian)

22. Yosefinejhad, A.; Chaharsooghi Amin, H.; Arayesh, B.; Elyasi, S. Factors Affecting the Adoption of Pressurized Irrigation Systems by Beneficiaries in Mehran City. Bull. Environ. Pharmacol. Life Sci. 2014, 3, 199-201.

23. Balali, H.; Saadi, H.; Vahdat Adab, R. Economic and Social Factors affecting on of Pressurized Irrigation Technology Acceptance by Wheat Farmers of Hamedan, Iran. J. Agric. Educ. Adm. Res. 2016, 37, 85-96. (In Persian)

24. Aghapour Sabaghi, M.; Ostvar, N. Barriers of pressurized irrigation development in shush city. Adv. Environ. Biol. 2012, 6, 254-260.

25. Shahzadi, E. Investigating Factors Influencing Adoption of Pressurized Irrigation Systems by Farmers. Case Study: Garmsar County, Iran. American-Eurasian J. Agric. Environ. Sci. 2013, 13, 115-120.

26. Bagheri, A.; Malekmohamadi, I. Behavior of acceptance of sprinkler irrigation by Ardabil farmers. J. Iran. Agric. Sci. 2005, 36, 1479-1488. (In Persian)

27. Amiri Ardakani, M.; Zamani, G.H. Difficulties and obstacles of use of under pressure irrigation systems in Kohkiloye and Boyerahmad provinc. Iran. J. Iran. Agric. Sci. 2004, 17, 230-243. (In Persian)

28. Madhava Chandran, K.; Surendran, U. Study on factors influencing the adoption of drip irrigation by farmers in humid tropical Kerala, India. Int. J. Plant Prod. 2016, 10, 347-364.

29. Amini, E. An investigation in to factors affecting the adopting of drip irrigation system in the plum gardens between 2002 and 2012 (case study). Indian J. Fund. Appl. Life Sci. 2014, 4, 660-666.

30. Surendran, P. Technology Acceptance Model: A Survey of Literature. Int. J. Bus. Soc. Res. 2012, 2, $175-178$.

31. Afrakhteh, H.; Armand, M.; Askari Bozayeh, F. Analysis of Factors Affecting Adoption and Application of Sprinkler Irrigation by Farmers in Famenin County, Iran. Int. J. Agric. Manag. Dev. 2014, 5, 89-99. [CrossRef]

32. Abdolmaleki, M.; Chizari, M. Impact of socio-economic characteristics on farmer's attitude and access to the information to adopt and utilize irrigation systems in Lorestan province, Iran. J. Ecol. Crop Plants 2011, 15, 77-87. (In Persian)

33. Afshar, N.; Zarafshani, K. An analysis of the tendency toward participating in water management: A case study of water users associations in the cities of Sefidbarg and Sarabbas, Kermanshah, Iran. Iran. J. Agric. Extens. Educ. 2010, 2, 99-113. (In Persian)

34. Norozi, A.; Chizari, M. Cultural factors-Social influence on City Nahavand wreath farmer's attitude about development of sprinkler irrigation. J. Iran. Agric. Extens. Educ. 2006, 2, 59-71. (In Persian)

35. Taqipour, M.; Abbasi, E.; Chizari, M. Farmers' Behavior toward Membership in Water User Associations (WUAs) in Iran: Applying the Theory of Planned Behavior. Eur. Online J. Nat. Soc. Sci. 2015, 4, 336.

36. Venkatesh, V.; Morris, M.; Davis, G.B.; Davis, F.D. User Acceptance of Information Technology: Toward a Unified View. J. MIS Q. 2003, 27, 425-478. [CrossRef]

37. Fishbein, M.; Ajzen, I. Predicting and Changing Understanding Behavior, the Reasoned Action Approach; Psychology Press, Taylor and Francis Group: New York, NY, USA, 2010.

38. Bagheri, A.; Ghorbani, A. Adoption and non-adoption of sprinkler irrigation technology in Ardabil Province in Iran. Afr. J. Agric. Res. 2011, 6, 1085-1089.

39. Bandura, A. Self-efficacy: Toward a unifying theory of behavioral change. Psychol. Rev. 1997, 84, 191-215. [CrossRef] 
40. Sharma, M.; Romas, J.A. Theoretical Foundations of Health Education and Health Promotion. 2012. Available online: www.Jblearning.com (accessed on 4 February 2015).

41. Molden, D.; Murray-Rust, H.; Sakthivadivel, R.; Makin, I. A water productivity framework for understanding and action. In Water Productivity in Agriculture: Limits and Opportunities for Improvement; Kijne, J.W., Barker, R., Molden, D., Eds.; CABI Publishing: Wallingford, UK, 2003; pp. 1-18.

42. Rogers, E.M.; Shoemaker, F.F. Diffusion of Innovation, 5th ed.; Free Press: New York, NY, USA, 2003.

(a) (1)

(C) 2018 by the authors. Licensee MDPI, Basel, Switzerland. This article is an open access article distributed under the terms and conditions of the Creative Commons Attribution (CC BY) license (http:/ / creativecommons.org/licenses/by/4.0/). 